Running head: Neurophysiological and psychological dimensions of fibromyalgia

\title{
An updated overview of the neurophysiological and psychosocial dimensions of fibromyalgia - a call for an integrative model
}

Ana Margarida Pinto, Msc,,${ }^{1,23}$ Rinie Geenen, $\mathrm{PhD},{ }^{4}$ Filipe Palavra, MD, ${ }^{5,6}$ Mark A. Lumley, PhD, ${ }^{7}$ Jacob N. Ablin, MD,${ }^{8,9}$ Kirstine Amris, MD, ${ }^{10}$ Jaime Branco, MD, ${ }^{11,12}$ Dan Buskila, MD, ${ }^{13}$ Miguel Castelo-Branco, $\mathrm{PhD}^{14}$ Leslie J. Crofford, MD, ${ }^{15}$ Mary-Ann Fitzcharles, MD, ${ }^{16}$ Mariana Luís, MD,${ }^{17}$ Tiago Reis Marques, $\mathrm{PhD}^{18,19}$ Jamie L. Rhudy, $\mathrm{PhD},{ }^{20}$ Lucina Q. Uddin, $\mathrm{PhD},{ }^{21}$ Paula Castilho, PhD, ${ }^{1}$ Johannes W. G. Jacobs, MD, ${ }^{22}$ and José A. P. da Silva, $\mathrm{MD}^{2,6,17}$

1. University of Coimbra, Center for Research in Neuropsychology and Cognitive and Behavioral Intervention (CINEICC), Faculty of Psychology and Educational Sciences, Rua do Colégio Novo, s/n, 3000-115 Coimbra, Portugal

2. University of Coimbra, University Clinic of Rheumatology, Faculty of Medicine, Rua Larga - FMUC, Pólo I - Edifício Central, 3004-504 Coimbra, Portugal

3. University of Coimbra, Psychological Medicine Institute, Faculty of Medicine, Rua Larga FMUC, Pólo I - Edifício Central, 3004-504 Coimbra, Portugal

4. Department of Psychology, Utrecht University, Martinus J. Langeveldgebouw, Heidelberglaan 1, 3584 CS Utrecht, The Netherlands

5. Centre for Child Development, Neuropediatric Unit. Pediatric Hospital, Coimbra Hospital and University Centre, Avenida Afonso Romão, 3000-602 Coimbra, Portugal

6. Coimbra Institute for Clinical and Biomedical Research (i.CBR), Faculty of Medicine, University of Coimbra, Azinhaga Santa Comba, 3000-548 Coimbra, Portugal

7. Department of Psychology, Wayne State University, 5057 Woodward Ave., Suite 7908, Detroit, MI 48202, USA

8. Internal Medicine H, Tel-Aviv Sourasky Medical Center, 6 Weizmann Street, Tel Aviv 6423906, Israel

9. Sackler School of Medicine, Tel Aviv University, Ramat Aviv 69978, Israel

10. The Parker Institute, Department of Rheumatology, Copenhagen University Hospital, Bispebjerg and Frederiksberg, Nordre Fasanvej 57, 2000 Frederiksberg, Denmark

11. Rheumatology Department, Egas Moniz Hospital - Lisboa Ocidental Hospital Centre (CHLO-EPE), R. da Junqueira 126, 1349-019 Lisbon, Portugal

12. Comprehensive Health Research Center (CHRC), Chronic Diseases Research Centre (CEDOC), NOVA Medical School, NOVA University Lisbon (NMS/UNL), Campo Mártires da Pátria 130, 1169-056 Lisbon, Portugal

13. Ben Gurion University of the Negev Beer-Sheba, Israel

14. University of Coimbra, Coimbra Institute for Biomedical Imaging and Translational Research (CIBIT), ICNAS, Edifício do ICNAS, Polo 3, Azinhaga de Santa Comba, 3000-548 Coimbra, Portugal, Portugal

15. Division of Rheumatology and Immunology, Department of Medicine, Vanderbilt University Medical Center, 1211 Medical Center Drive, Nashville, TN 37232, USA

16. Division of Rheumatology, Department of Medicine, McGill University, 1650 Cedar Ave, Montreal, Quebec, Canada, H3G 1A4

17. Rheumatology Department, Coimbra Hospital and University Centre, Praceta Mota Pinto, 3004-561 Coimbra, Portugal

18.Psychiatric Imaging Group, MRC London Institute of Medical Sciences (LMS), Hammersmith Hospital, Imperial College London, South Kensington, London SW7 2BU, UK 19. Department of Psychosis Studies, Institute of Psychiatry, Psychology and Neuroscience, Kings College London, Strand, London WC2R 2LS, UK

20. Department of Psychology, University of Tulsa, 800 S Tucker Dr, Tulsa, OK 74104, USA

21. Department of Psychology, University of Miami, 1320 S Dixie Hwy, Coral Gables, FL 33146, USA 
Running head: Neurophysiological and psychological dimensions of fibromyalgia

22. Department of Rheumatology \& Clinical Immunology, University Medical Center Utrecht, Heidelberglaan 100, 3584 CX Utrecht, Netherlands

\section{Corresponding author}

José António Pereira da Silva, MD, $\mathrm{PhD}$

Serviço de Reumatologia

Centro Hospitalar e Universitário de Coimbra

Praceta Mota Pinto

3004-561 Coimbra, Portugal

E-mail: jdasilva@chuc.min-saude.pt

\section{Competing interests}

Paula Castilho, Rinie Geenen, Mark Lumley, Filipe Palavra, Jacob Ablin, Kirstine Amris, Jaime Branco, Dan Buskila, Miguel Castelo-Branco, Leslie Crofford, Mary-Ann Fitzcharles, Mariana Luís, Jamie Rhudy, Johannes Jacobs, Lucina Uddin, and José A.P. da Silva declare they have no competing interests.

Tiago Reis Marques reports personal fees from Lundbeck, Astellas, Janssen, and Angelini outside the submitted work.

AMP is the holder of a PhD Grant (SFRH/BD/145954/2019), sponsored by the Portuguese Foundation for Science and Technology (FCT), the Human Capital Operational Programme (POCH), and the European Union (UE), and was financially supported (through stipend) for this work by the Coimbra Rheumatology Association (ARCo) and the Portuguese Society of Rheumatology (SPR). 
Running head: Neurophysiological and psychological dimensions of fibromyalgia

\begin{abstract}
:
Research into the neurobiological and psychosocial mechanisms involved in fibromyalgia (FM) has progressed remarkably in recent years. Despite this, currents accounts of FM fail to capture the complex, dynamic and mutual crosstalk between neurophysiological and psychosocial domains.

We conducted a comprehensive review of the existing literature in order to synthesise current knowledge on FM, explore and highlight multi-level links and pathways among different systems and build bridges between existing approaches. An extensive panel of international experts in neurophysiology and psychosocial aspects of FM discussed the collected evidence and progressively refined and conceptualized its interpretation.

Fibromyalgia is a complex condition resulting from the dynamic interplay between multiple systems and processes. We provided an updated overview of the most relevant observations in FM to date as well as the potential pathways by which they exert they are related and exert their mutual influence, to produce the manifestations commonly associated with FM.

This review constituted the first step towards and supported the development of a much needed model capable of integrating the main factors implicated in FM into a single, unified model that may prove valuable in understanding and managing FM.
\end{abstract}

Keywords: Fibromyalgia, comprehensive review, neurophysiological abnormalities, psychosocial processes, integration 
Running head: Neurophysiological and psychological dimensions of fibromyalgia

\section{Introduction}

Fibromyalgia (FM) is a complex and disabling condition that affects $2-5 \%$ of the general adult population, ${ }^{1,2}$ with a higher prevalence among women, ${ }^{3}$ and imposes a heavy burden on individuals, families and society. ${ }^{4-7}$

Generalised musculoskeletal pain and tenderness have long been recognised as the most distinctive features of $\mathrm{FM}^{8}$ although many other (equally) distressing somatic, cognitive and affective symptoms such as fatigue, sleep disturbance, cognitive impairment and emotional distress are also often present. ${ }^{9,10}$

Over the last decades the concept and clinical operationalization of FM has change considerably, with several modifications ${ }^{9-11}$ to the classification criteria initially proposed $^{8}$. Notwithstanding relevant advances on FM research ${ }^{12}$ there is still the need for an integrative model capable of bridging the gap between different current perspectives of FM.

Here, we provide the main findings of a literature review we conducted on the pathophysiology and psychosocial dimensions of fibromyalgia (FM) as well as their interpretation. This review along with the insights of international experts in the field served as a basis for the development of an integrative model of FM. ${ }^{13}$

\section{Published Observations on FM Pathophysiology and their interpretation}

\section{Abnormalities of the nervous system: FM as a primary disorder of pain modulation}

The predominant current paradigm describes FM as a disorder of pain processing by the central nervous system (CNS) leading to the core phenomenon of central amplification of pain. ${ }^{14}$ This concept is supported by significant biological evidence. ${ }^{15-18}$

Repeated stimulation of synapses typically leads to structural and functional changes ${ }^{19,20}$ that favour the amplification of the output. This synaptic remodelling after temporal summation of painful stimuli has been demonstrated at multiple levels of the CNS, including the spine, the insular and the anterior cingulate cortices, the primary somatosensory cortex and the medial prefrontal cortex. ${ }^{21-23}$ This mechanism has been implicated in the development of ectopic and aberrant inputs and in the disinhibition of the primary somatosensory cortex, which seems to occur in patients with FM. ${ }^{24}$

In addition to these subcellular and cellular processes and to other morphological alterations involving for example grey matter volume and density ${ }^{25}$, a higher level of neurobiological dysfunction has been extensively characterised in FM. Many neuroimaging studies indicate an abnormally high level of activation in brain areas involved in the anticipation of (medial frontal cortex), attention to (dorsolateral prefrontal cortex, dorsal anterior cingulate cortex) and perceptual/emotional aspects of pain (insula and subcortical structures such as the amygdala, thalamus, and cerebellum), supporting the notion of a widespread network dysfunction in this clinical condition. ${ }^{26-28}$ Conversely, low activity is typically described in the prefrontal cortex (namely on its lateral aspect), anterior cingulate cortex and the brainstem, which has been interpreted to reflect impairment in descending pain inhibition pathways. ${ }^{29,30}$

Interestingly, studies have shown that chronic pain, including FM, is associated with hyperactivation (actually, a failure in the deactivation of nuclear regions) of the default mode network (DMN), one of the prototypes of the functional magnetic resonance imaging (fMRI) resting-state networks. ${ }^{31}$ Studies also concur in the existence of a decreased connectivity of the medial prefrontal cortex with the posterior components of 
Running head: Neurophysiological and psychological dimensions of fibromyalgia

the DMN and an increased connectivity with the anterior cingulate and the insular cortex, which seem to be proportional to the intensity of pain. ${ }^{32}$ These neurophysiological observations may also account for clinical correlates: they corroborate a certain level of tonic pain processing activation and support the increased emotional and attentional exacerbation of pain stimuli, as observed in FM.

Some authors have referred to these changes as a "gain in pain" 33 or an "increased volume control setting", ${ }^{34}$ meaning that proprioceptive or mildly nociceptive sensorial afferents are augmented, without "brakes", into (highly) nociceptive perceptions that promote and amplify suffering. ${ }^{35}$

Central sensitisation is also presumed to be at the root of the multisensory hypersensitivity commonly reported by patients with FM, although further studies are needed to understand the operating mechanisms. ${ }^{17}$ Such observations represent invaluable progress, but they still do not unveil the origin of the primary causative factor(s). As described below, genetic vulnerability and epigenetic changes have been suggested as a potential source of central sensitisation. ${ }^{17,35}$ Also, nociceptive inputs are considered an essential factor in inducing and maintaining central sensitisation, ${ }^{36}$ with pain being its main clinical consequence.

Once the pathological alterations described above have been established in an individual, they will be activated and amplify pain by any impending noxious stimulus, independently of its nature. ${ }^{35}$

\section{Other abnormalities of the central or peripheral nervous system}

A potential source of primary pain in FM is suggested by studies that indicate the (co-)existence of a small-fibre pathology, characterized by structural and functional changes in the peripheral nervous system of these patients. ${ }^{37}$ According to a metaanalysis, small-fibre pathology seems to be a prevalent phenomenon, affecting nearly half of the patients with FM. ${ }^{38}$

At a morphological level, peripheral abnormalities may encompass decreased thickness of nerve fibres in skin and cornea, autonomic denervation, and enhanced innervation of microvascular structures. ${ }^{37}$ Functional changes, in turn, may occur along the somatosensory pathway, resulting in altered pain thresholds as well as altered microcirculation and nerve conduction. ${ }^{37}$

Changes can also be observed in muscle fibres of patients with FM, although conflicting results have been reported ${ }^{39}$. Examples include atrophy, inflammation, hypoxia, ischemia and tension in different muscle fibres as well as changes in functional parameters such as muscle fatigue. ${ }^{39,40}$ Such abnormalities seem to be associated with metabolic and biochemical changes. Research has shown reduced levels of high-energy phosphates (and respective metabolites) and other phosphates essential to muscle activity as well as augmented concentrations of neuromodulators and excitatory neurotransmitters, proinflammatory cytokines and glycolysis products. ${ }^{39,41}$

Collectively, these abnormalities could explain a state of hyperexcitability and sensitisation, leading to an augmented tonic nociceptive input from the periphery and even to spontaneous nociceptive firing. ${ }^{39,40}$ Despite some empirical findings supporting this concept, the nature of such abnormalities remains undetermined ${ }^{37}$ and its relative contribution to FM a matter of debate. ${ }^{42,43}$ Recent work has added even more complexity to this already puzzling issue, not only by showing that small-fibre involvement occurs in many other pain-related and unrelated disorders beyond $\mathrm{FM}^{44}$ but also by lending preliminary support to the concept that structural changes in the peripheral nervous 
Running head: Neurophysiological and psychological dimensions of fibromyalgia

system may be driven by biochemical imbalances in specific brain regions (e.g., the insula). ${ }^{45}$

An autonomic dysfunction characterised by tonic sympathetic hyperactivity and parasympathetic hypoactivity (particularly during night time) along with an overall blunted sympathetic response to stress has been indicated in FM. ${ }^{46,47}$ This has been further supported by observations of abnormalities in heart rate variability (HRV) of patients with $\mathrm{FM},{ }^{47,48}$ including low vagal tone, which is considered to be a putative biomarker of chronic stress. ${ }^{49}$

Although some studies have pointed out that aberrations in the hypothalamus-pituitaryadrenal (HPA) axis and in the autonomic nervous system (ANS) are associated with an increased susceptibility to develop chronic widespread pain (CWP), ${ }^{50,51}$ it remains unclear whether these dysregulations are a precursor of FM, a byproduct of the functional decline associated with this condition, or a surrogate marker of a co-factor, namely stress. $^{12,52}$

In fact, these abnormalities may stem from many other confounding factors, including medication use ${ }^{53}$ presence of comorbidities ${ }^{54}$ or trauma history, ${ }^{55}$ that are not always accounted for in studies investigating the association between HPA/ANS abnormalities and FM. Moreover, depressive or anxiety disorders that are typically related to hypercortisolemia may mask hypocortisolemia in FM. ${ }^{56}$ Overall, a meta-analysis and meta-regression did not find diminished levels of cortisol in FM. ${ }^{57}$ Confounding factors may partially explain not only the conflicting findings, with different HPA activity patterns being reported across studies, but also the fact that these abnormalities are nonspecific and circumscribed only to a subset of patients with FM. ${ }^{17,39}$ It is also important to note that different designs, methods and measurements may also underlie and help explain apparently divergent findings.

Future longitudinal and methodological sound studies not limited to both cortisol levels and HPA axis responsiveness may provide better insight into HPA axis functioning and the nature of a possible link between these abnormalities and FM.

Chronic stress may lead to dysregulation of the HPA axis that in turn will result in abnormalities in the regulatory function of neuroendocrine mechanisms which may favour a chronic pro-inflammatory status. ${ }^{58}$ In line with this, (neuro)inflammation has also been advocated to play a role in FM based on observations of inflammatory signals in the cerebrospinal fluid, the spinal cord, and peripheral nerve endings. ${ }^{59-61}$ The release of pro-inflammatory and neuroactive substances that lead to the recruitment and activation of local immune cells, ${ }^{62}$ may contribute to sensitisation processes and clinical symptoms. ${ }^{59,61}$ Such observations tentatively supported suggestions that FM should be seen as an inflammatory disease of the $\mathrm{CNS}^{63}$ equivalent to the labelling of a sister condition, chronic fatigue syndrome, as "myalgic encephalomyelitis". Noteworthy, similar immune changes in the CNS, and even in the peripheral blood, are commonly observed in psychopathological conditions that are often comorbid with FM and chronic fatigue syndrome, such as depression, anxiety disorders, and post-traumatic stress disorder (PTSD). ${ }^{64-66}$ Despite this, the nature and exact role of inflammation in FM development need to be further clarified by future studies. ${ }^{59}$

Given its bidirectional crosstalk with the brain and regulatory influence upon multiple body functions ${ }^{67}$ as well as its involvement in various psychiatric, centrally-driven, and immune-mediated disorders, ${ }^{68,69}$ some of which recognized comorbidities of FM, the microbiome-gut-brain axis has received increased attention in recent years. 
Running head: Neurophysiological and psychological dimensions of fibromyalgia

A recent study ${ }^{70}$ revealed significant differences in the gut microbiome of patients with FM when compared to healthy controls, with the former displaying an altered faecal microbiome profile characterised by an altered abundance of several bacterial taxa. This variance in the microbiome composition of patients with FM was uniquely associated with FM symptoms severity and, most importantly, it demonstrated good discriminative properties in classification analysis, with an area under the receiver operating characteristic (ROC) curve of $87.2 \%$. Even though promising, the study of the microbiome in chronic pain, and particularly in FM, is still in its infancy. Future studies aimed at clarifying the exact nature of these microbiome alterations as well as their (specific) role in FM development and pathophysiology are necessary.

\section{Genetic predisposition}

There is data to support a genetic predisposition to CWP and FM: nearly $50 \%$ of the variance in CWP/FM symptoms has been ascribed to polygenic inheritance. ${ }^{71,72}$

Familial aggregation studies have shown that first-degree relatives of individuals with FM (e.g., siblings, offspring) present, compared to controls, lower pressure pain thresholds and a significantly greater risk of developing FM. ${ }^{73-76}$ This familial aggregation occurs not only for FM, but also for certain personality traits (e.g., harmavoidance $)^{77}$ and affective disorders ${ }^{74,78}$ associated with FM. Studies that have attempted to distinguish between genetic and environmental influences found familial aggregation of FM and increased vulnerability to CWP to be largely attributable to genetic influences, with shared environment playing a minor role. ${ }^{71,75}$

Several genetic polymorphisms involving serotoninergic, catecholaminergic, dopaminergic, glutamatergic, canabinoidergic, and adrenergic systems have been associated with both a higher risk of developing FM, and clinically more severe FM. ${ }^{79,80}$ Similar observations have been made regarding genes encoding voltage-gated ion channels and regulating binding proteins, and in neuroplastic pathways. ${ }^{79,80}$, Although results are frequently inconclusive or contradictory, almost all genes proposed as risk factors for FM are related to neurotransmitters and their receptors, which makes them liable to play a part in each of the biological mechanisms described previously. This also makes them capable of interfering or enhancing psychosocial dimensions and factors. In fact, some of these polymorphisms have also been recognised as risk factors for other affective and pain-related disorders, indicating a shared genetic risk that may, at least partially, account for the high comorbidity between FM and these disorders. ${ }^{79-81}$ Based on the observation that FM is associated with hypomethylation of genes putatively implicated in autonomic and stress responses and subcortical aberrations, it has recently been proposed that epigenetic (dys)regulation may play a role in FM development. ${ }^{82}$

\section{Medical comorbidities}

FM often co-occurs, in a lesser or greater degree, with other physical disorders, potentially leading to greater disease burden and negatively impacting clinical outcomes, response to treatment and clinical decision making. . $^{83,84}$

Specifically, FM has been associated with chronic fatigue syndrome, irritable bowel syndrome, headaches, dysmenorrhea, temporomandibular disorder, interstitial cystitis/painful bladder syndrome and regional pain syndromes, suggesting the existence of mutual pathophysiological mechanisms and clinical aspects. ${ }^{85,86}$ Such comorbidity and shared pathophysiology have led researchers to subsume FM under varying umbrella 
Running head: Neurophysiological and psychological dimensions of fibromyalgia

terms, each one emphasizing distinctive features, such as central sensitivity syndromes, ${ }^{87,88}$ functional somatic syndromes ${ }^{89}$ or chronic overlapping pain conditions. ${ }^{90}$ FM is also found to occur in immune-mediated and degenerative rheumatic diseases, including rheumatoid arthritis, systemic lupus erythematosus, scleroderma, Sjögren's syndrome, spondyloarthropathies, and osteoarthritis, ${ }^{83,84,91}$ and neurological diseases such as multiple sclerosis, ${ }^{92}$ probably due to unfolding central sensitisation. This mechanism is also postulated to underlie the association between FM and some generalised joint hypermobility-related syndromes. ${ }^{93}$

Similarly, an association between FM and allergic diseases has been reported, potentially driven by an altered expression of immunoregulatory genes. ${ }^{94}$ Cardiovascular disease and diabetes are also comorbidities of FM..$^{83,84}$

Obesity is not only frequent among patients with FM, but also a risk factor for its development. ${ }^{95}$ Studies have shown obesity in FM to be associated with greater clinical symptoms, emotional distress, functional impairment, medicine consumption, multimorbidity, and lower quality of life. ${ }^{96-98}$ Although the exact nature of the association between obesity and FM is still elusive, the potential pathogenic effect of some factors including an inactive lifestyle, sleep disturbances/deprivation, emotional distress, neuroendocrine dysfunction, and aberrations in endogenous modulatory function has been underscored. ${ }^{99}$

\section{Psychosocial dimensions}

\section{A) Psychiatric comorbidities}

In a comprehensive review of fibromyalgia, it is reported that mood and anxiety disorders are common among patients with FM, with point-prevalence values varying between 13 $48 \%$ and $27-60 \%$ and lifetime prevalence ranging between $20-86 \%$ and $16-60 \%$, respectively. ${ }^{39}$ Another systematic review with meta-analysis reported that the overall pooled point-prevalence of major depressive disorder in patients with FM varied between $25 \%$ and $45 \%$, depending on the assessment methods applied, while lifetime prevalence reached $65 \%{ }^{100}$ Authors also draw attention to the tendency of screening tools, particularly those based on self-report, to overestimate the prevalence of depression in FM when compared to more in-depth methods such as clinical interviews. Overall, depressive and anxiety symptoms scores are significantly greater than those reported in community samples and other pain-related disorders. ${ }^{39}$ Also, PTSD and FM show considerable similarities and frequent co-existence. ${ }^{39,101}$

Sleep disturbances have been shown to predict $\mathrm{CWP} / \mathrm{FM},{ }^{102,103}$ and to negatively influence pain (and be influenced by it), fatigue and emotional distress levels, ${ }^{104,105}$ with authors suggesting that it may constitute a transdiagnostic factor across affective disorders and FM. ${ }^{106}$ Findings suggest that the relationship between sleep and pain may be centrally mediated. ${ }^{104,107}$ Apart from awaking unrefreshed, which constitutes a key symptom of FM, sleep disorders such as restless leg syndrome ${ }^{108}$ are also common in FM.

A brief review concluded that when compared to healthy controls, patients with FM tend to present a higher prevalence of personality disorders. ${ }^{109}$ In a community sample, $13.3 \%$ of the participants met the diagnosis for at least one personality disorder, whereas in patients with FM the prevalence reached 31.1\%. ${ }^{110}$ Avoidant, Dependent, and ObsessiveCompulsive Personality disorders, commonly referred as Cluster C Personality disorders (which have marked fear and anxiety as hallmark), ${ }^{111}$ seem to be the most prevalent personality disorders in FM. ${ }^{109}$ The rate of reported comorbidity between FM and 
Running head: Neurophysiological and psychological dimensions of fibromyalgia

personality disorders is extremely variable and may depend on the setting in which it is taken (clinical or research) and the kind of assessment performed (self-report or diagnostic interview).

\section{B) Psychological vulnerability and resilience factors}

Cognitive and affective processes have long been established as relevant modulators of pain perception and processing, above and beyond the effect of the nociceptive stimulus itself, both in clinical and non-clinical populations. ${ }^{112-114}$

Over time, research has mainly focused on the identification of processes that may negatively influence pain experience and hamper adjustment to FM. These include, among others, pain-specific cognitions (such as pain catastrophizing, ${ }^{115-118}$ negative expectations $^{119}$, and attributions ${ }^{120}$ ), specific ways of emotion processing such as alexithymia $^{121}$, and vulnerability to invalidation by others. ${ }^{122}$ Remarkably, the same observations apply to general psychological traits and processes that reflect misery and suffering. These include disordered affect characterised by high negative affect and blunted positive affect, ${ }^{123,124}$ low levels of perceived control and self-efficacy, ${ }^{125}$ and maladaptive cognitive-emotion regulation strategies. ${ }^{126}$

More recently, psychological resilience factors have attracted attention. ${ }^{127,128}$ They include factors such as positive affect, pain acceptance, optimism, active-pain coping, psychological flexibility, purpose in life, and values-based action. ${ }^{129-132}$ Studies highlight that the soothing influence of positive affect upon pain perception operates through the downregulation of dysfunctional cognitive-affective processes and the promotion of adjustment and resilience by broadening awareness and fostering psychological and behavioral flexibility. ${ }^{133-135}$

It is noteworthy that most of the psychological factors with aggravating impact upon pain are commonly expressed in high (i.e., disruptive) levels by patients with FM whereas the opposite is seen regarding resilience factors, such as positive affect. ${ }^{123,124}$

Nevertheless, psychological profiles of people with FM differ. One study guided by operant learning theory could differentiate a 'dysfunctional group' characterised by poor coping strategies, an 'interpersonally distressed group' characterised by interpersonal difficulties, and 'adaptive copers' characterised by adequate coping strategies. ${ }^{136}$ Another study using subjective and objective measures distinguished five FM subgroups, labelled 'Adapted', 'Fit', 'Positive', 'Poor performer', and 'Maladapted'. ${ }^{137}$ These studies suggest that there is a wide range of coping and personality styles in FM and that not all of them are maladaptive nor do all patients report high levels of distress.

Regarding affective factors, a large body of evidence has systematically demonstrated, with few exceptions, that positive affect decreases pain perception and increases pain tolerance, whereas negative affect has the opposite effects. ${ }^{138-140}$

Emotions have also been shown to shape, to a greater or lesser degree, diverse physiological responses to pain, including defensive reflexes, electrodermal activity, heart rate, and blood pressure ${ }^{141-144}$ as well as to salient sensory stimuli other than pain, as for example sound. ${ }^{145}$

While valence (i.e., the experienced "goodness" (positive valence) or "badness" (negative valence) of an event, object, or situation) determinates the nature of the modulation (e.g., facilitation vs inhibition), the strength of the modulatory effects seems to be determined by the interaction between valence and arousal. ${ }^{140,143}$ Several stimulus modalities (i.e., odours, pictures, music), ${ }^{139}$ have been shown capable of producing this modulatory action. Furthermore, the effects of emotions upon pain do not depend on them being 
Running head: Neurophysiological and psychological dimensions of fibromyalgia

related to pain itself or not: they will be operative as long as they are perceived as personally relevant. ${ }^{140}$

Converging lines of evidence have shown that emotions influence the processing of pain both bottom-up (e.g., multisensory integration) and top-down (e.g., descending inhibition) through spinal and supraspinal mechanisms. ${ }^{139}$ Placebo and nocebo effects are clear examples of these phenomena and they seem to produce hypoalgesia or hyperalgesia through the same modulatory systems engaged by emotions. ${ }^{112}$

Nonetheless, some studies have shown mixed findings regarding emotional modulation in patients with FM. Specifically, in a study, patients with FM did not have amplified neuroautonomic responses to negatively charged pictures, despite describing amplified subjective ratings on valence and arousal. ${ }^{146} \mathrm{~A}$ study found startle response to be inhibited rather than enhanced in response to unpleasant pictures, ${ }^{147}$ while in another study, ${ }^{144}$ a hyporesponsive ANS to elicited emotions in FM was not observed. Regarding the effect of positive stimuli, a study did not find any evidence of disrupted appetitive processing ${ }^{146}$ while two other studies reported a diminished appetitive activation and emotional modulation of pain. ${ }^{147,148}$

Such inconsistency across studies may be related to sampling (patients' characteristics) and methodological issues (differences in stimuli and measurements), (des)sensitisation processes, the engagement of different defensive responses (e.g., fear vs anxiety responding, the inhibitory "freeze" response), and blunted autonomic responses to acute stressors, which is typical of chronic stress conditions, including FM. Nonetheless, future studies are certainly warranted for further clarification.

One thing is clear: a deeper understanding of the close link between emotion and pain (and underlying mechanisms) and the inclusion of "emotional work" in the care of patients seem to be key for a better management of pain in general ${ }^{149}$ and of FM in particular.

The key role of cognitive-affective mechanisms in the perception and modulation of pain is further supported by the effectiveness of interventions targeting self-regulation and psychological processes. Additional support comes from studies using biofeedback, which have shown that, following a period of training using real-time neuroimaging, individuals can become proficient in reducing the activation of brain regions involved in pain processing, thus reducing the concurrent perception of experimentally-induced pain. ${ }^{150}$ The same can be achieved by consciously controlling apparently autonomous physiological processes involved in pain and emotion, such as HRV and muscle tone. ${ }^{151,152}$ Other techniques and interventions as for example hypnosis ${ }^{153}$ and cognitivebehavioral therapies, including the more recent contextual approaches such as mindfulness and acceptance and commitment therapy, seem to have an analogous effect, being associated with changes in the activity level ${ }^{154,155}$ and connectivity of certain brain structures. $^{156-159}$

\section{C) Temperament and personality}

Several studies examined the link between personality characteristics and FM. Such work has looked for a particular personality profile that renders people more vulnerable or resilient to the development of FM. Published studies have presented inconclusive findings, failing to demonstrate the existence of a specific personality profile capable of discriminating patients with FM from healthy controls at the individual level. ${ }^{160-162}$

Understanding the relationship between FM and personality is further complicated by the fact that chronic pain and its associated emotional states may change not only the report 
Running head: Neurophysiological and psychological dimensions of fibromyalgia

of personality traits, ${ }^{163}$ but even personality itself, as suggested by neuroimaging studies. ${ }^{164}$

Despite these limitations, certain personality traits have been identified as common in chronic pain ${ }^{165}$ and FM. Depending on the personality profiling tools used, FM has been associated with greater expression of neuroticism/harm-avoidance and reduced levels of extraversion and self-directedness. ${ }^{166-168}$ Harm-avoidance in particular may be relevant given its reported association with deficient pain modulation ${ }^{169}$ and with affective symptoms. ${ }^{170}$

Perfectionism, type D personality, and alexithymia have also been associated with pain and other bodily symptoms as well as emotional distress and negative cognitive processes. $^{121,160,171-173}$

In a study, members of our group have demonstrated that health professionals experienced in managing FM can distinguish patients from controls, as a group, based on single items of a personality profiling tool (NEO-PI-R). ${ }^{174}$ Each individual health professional, using items of his/her choice, showed in ROC analyses an AUC of 0.71-0.81 in predicting the diagnosis, with no relevant differences between rheumatologists and psychologists. The most predominant items indicated high levels of neuroticism and low levels of trust.

Yet, these associations do not necessarily demonstrate causality, but constitute small pieces of a very complex puzzle. Remarkably, however, in a longitudinal study, a high level of neuroticism has been shown to precede and predict joint pain over a follow-up of 23 -years. ${ }^{175}$ Similarly, a 25 -year longitudinal study, showed that neuroticism was associated with an increased risk of developing physical diseases, in particular, those characterised by chronic systemic pain (e.g., odds ratio $=1.37,95 \% \mathrm{CI}=[1.28-1.47]$ for CWP). ${ }^{176}$

Studies examining the potential protective role of positive dispositional features are scarce. ${ }^{177}$ Moreover, it remains underexplored whether and how different traits interact with each other to amplify or attenuate FM diathesis. In fact, it may be hypothesized that peculiar combinations of dispositional vulnerability and resilience factors may result in greater predictive specificity than individual traits themselves.

\section{D) Traumatic life events}

Research has consistently shown that recall of exposure to different types of early life stress (e.g., adverse interpersonal contexts, abuse and neglect, loss or rejection), is a common experience among many individuals with $\mathrm{FM},{ }^{178,179}$ although studies based on patients' self-report are prone to recall bias. ${ }^{180}$ Nevertheless, recall should be taken seriously, because the memory of past stressors may give a better reflection of one's current reality than the actual events in the past.

While recognizing methodological limitations in the available evidence, a study ${ }^{178}$ concluded that early experiences of physical and sexual abuse were significantly associated with subsequent onset of FM. This link between adverse experiences involving physical and psychological trauma and FM development has been confirmed by many other reviews on the topic. ${ }^{181-183}$

The importance of such findings is underlined by longitudinal studies demonstrating that experiences of adverse early life events represent an important risk factor for developing somatic symptoms, including CWP, later in life. ${ }^{184-186}$ Using a representative sample from the UK, it was found that financial hardship and low education level (this one only for men) in early adulthood were prospectively associated with an increased risk of CWP. ${ }^{185}$ In a study conducted using data from the prospective 1958 British Birth Cohort Study, ${ }^{186}$ the authors found that individuals who had experienced adverse life events in childhood 
Running head: Neurophysiological and psychological dimensions of fibromyalgia

such as socioeconomic disadvantage, maternal death, and living in institutional care, were at higher risk of developing CWP later in life, even after controlling for psychosocial variables.

Studies on the impact of early adversity have also shown that quantity matters. The number of adverse events (and corresponding cumulative effect) is more likely to contribute, in a dose-dependent manner, to the development of chronic pain than the particular type of event individuals have been exposed to, even when controlling for potential sociodemographic, affective, and clinical confounders. ${ }^{187}$

One possible pathway through which traumatic events, such as abuse, impact on pain severity and (dys)function is via affective distress and fibromyalgia-ness ${ }^{188}$ (also referred to as polysymptomatic distress, representing the distribution of FM symptoms along a continuum $^{189}$ ).

Other explanation for the pernicious effect of early adversity is that by hinder effective socioemotional development and regulation, it drives the body to a "wear and tear" state due to stress buildup (allostatic load), which in turn may disrupt the balance between inhibitory-facilitatory processes and favour central sensitisation. ${ }^{187,190}$ Indeed, even after adjusting for depressive symptoms, healthy individuals with high levels of adversity showed both greater central sensitisation and attenuated autonomic pain responses. ${ }^{190}$

Interestingly, there is some evidence that adverse early experiences may be associated with inflammation, life-long aberrations in the HPA and ANS function, epigenetic modifications in the regulation of gene expression for neurotransmitters (e.g., serotonin and dopamine) and other endogenous proteins, and reprogramming of the nociceptive and descending inhibitory circuitries, ${ }^{183,191-193}$ all of which may directly or indirectly contribute to central amplification, the hallmark of FM. Nonetheless, prospective studies aimed at clarifying this link are warranted.

\section{E) Social Environment}

An increasing body of evidence supports the role that social determinants (e.g., social connectedness, social support) and milieu may have on health indicators, including pain and psychopathological symptoms. ${ }^{194}$ Humans depend on others - on their protection, caring and cooperation - to thrive and reproduce and are thus fundamentally predisposed to connect and form social bonds. ${ }^{195,196}$ So, potential threats or actual failure to meet this basic interpersonal need may translate into an increased likelihood of developing an array of mental and physical symptoms and disorders, ${ }^{197,198}$ including pain. For example, social disconnection and social distress have been shown to negatively influence pain ratings in patients with $\mathrm{FM}^{199}$ and pain-related responses in healthy subjects. ${ }^{200}$ Longitudinal studies have found an association between social isolation/loneliness and worse functional status, greater levels of pain interference, depression and fatigue in clinical and non-clinical samples. ${ }^{201,202}$

Vice versa, social connection has been increasingly recognized as a contributor to mental and physical well-being. It was found that social support has a buffering effect upon pain, ${ }^{203}$ although recent findings have further proposed that this pain-attenuating effect seems to be dependent on several intrapersonal and interpersonal factors, including attachment styles, participant-partner relationship, and type of interpersonal interaction. ${ }^{204}$ Also, the perceived quality of social support (rather than quantity) plays a role when predicting FM-related outcomes. ${ }^{205}$

Also, research indicates that social support has a buffering effect against negative painrelated outcomes, probably through its soothing influence on cognitive and affective processes involved in pain processing and modulation. ${ }^{194,203,206}$ 
Running head: Neurophysiological and psychological dimensions of fibromyalgia

The importance of these findings is underscored by repeated observations that patients with FM exhibit greater social isolation/loneliness (even when compared to patients with other pain disorders), less perceived social support, and increased perception of invalidation from others. ${ }^{122,207-209}$ Interpersonal difficulties are thought to make patients with FM more vulnerable to the negative effects of multiple sources of stress. ${ }^{209}$

\section{F) Multisensory hypersensitivity}

Studies have shown that the hypersensitivity observed in FM is not limited to pain but that it often extends to other non-nociceptive sensory modalities, with patients showing an augmented sensitivity to tactile, olfactory and auditory stimuli. ${ }^{210-214}$ This multisensory hypersensitivity, which is linked to altered brain activity patterns in sensory areas and areas implicated in sensory integration, ${ }^{215}$ has been found to be a distinctive neurophysiological feature in $\mathrm{FM}^{216}$ and a potential endophenotypic marker of central sensitisation. ${ }^{17}$ In fact, this link between perceptual amplification and central sensitisation had already been proposed by previous studies. ${ }^{211,214}$

Another potential mechanism that has been advocated to explain this phenomenon is generalised hypervigilance, although this hypothesis remains controversial. According to this hypothesis, patients with FM tend to pay excessive attention to internal (i.e., bodily perceptions) $)^{217,218}$ and external cues and to present an exaggerated, sometimes painful, response to somatosensory stimuli, even those otherwise innocuous or insignificant. 210,211,213,219

While patients tend to consistently report increased subjective hypervigilance and show on average a stronger orientation towards threats, ${ }^{212,215,218}$ results regarding the experimental demonstration of perceptual amplification are less convincing. ${ }^{213,217,219-222}$ Sampling and methodological differences as well as distinct operational definitions of the concept of hypervigilance may be at the core of such marked inconsistency across studies. For example, a study distinguished two types of heightened body awareness: one maladaptive related to hypervigilance, where a threat-focused monitoring of body sensations predominates; and the other adaptive, characterised by an attunement with and through the body, ${ }^{223}$ that facilitates the processing and integration of information relevant for self-regulation. ${ }^{224}$ It seems that patients with FM tend to present this former, pernicious form of body awareness. ${ }^{224}$

Future studies should take both types of body awareness into consideration, which may establish and further clarify the role of hypervigilance in FM. Also the hypothesis of affiliating the process of sensory hypervigilance to catastrophizing and rumination and both of them to a hyperactive DMN observed in FM is tempting.

Altogether, these observations suggest that patients with FM seem to be subjected to a (perceived) overload of psychological and sensorial input that tends to take a predominantly negative valence. Whatever their origins, it seems plausible that the increased subjective sensitivity to different sources of stimuli coupled with negative cognitive-affective states and processes evolve into a reverberant source of additional stress, anxiety and fatigue in FM. ${ }^{212}$

As a consequence, maladaptive avoidance and isolation behaviours may ensue, ${ }^{224}$ in a failed attempt to bypass the (perceived) continuous input storm. ${ }^{212}$

\section{Gender differences}

Gender differences in pain are a relevant topic, considering that many chronic pain conditions, including FM, are more prevalent and severe among women. ${ }^{225}$ Research has 
Running head: Neurophysiological and psychological dimensions of fibromyalgia

demonstrated that, compared to males, females have, overall, higher sensitivity to experimental-induced pain, higher tendency to pain amplification, and lower endogenous pain inhibition. ${ }^{226-228}$

Research on the mechanisms underlying this gender-related variability in pain perception and processing has stressed their multifactorial nature, with biological and psychosocial factors contributing to the phenomenon. ${ }^{229,230}$ Among the biological factors, both sex hormones (hormone levels, interaction with the opioidergic system, anti or pronociceptive action) and menstrual cycle have been shown to influence responses to experimentallyinduced pain as well as emotional modulation of pain. ${ }^{228,229,231}$ While sex-dependent genetic associations have been shown to affect pain perception, also sex-differences in other systems implicated in pain modulation, such as autonomic nervous system activity and supraspinal connectivity, have been noted. 228,229

Psychosocial factors accounting for gender-differences in pain include social interaction, gender role expectations regarding pain sensitivity and pain expression and genderrelated personality traits, such as masculinity/femininity. ${ }^{230,232}$ Additionally, a sexdependent effect of past pain experiences ${ }^{233}$ and adverse experiences in childhood ${ }^{234}$ on pain sensitivity has been demonstrated, with this association being significant only for females. At a more intrapersonal level, variation in psychological distress and psychological processes such as pain catastrophizing, self-efficacy, and coping strategies also seems to contribute to the reported gender-differences. ${ }^{228,230}$

\section{Conclusion}

Despite all advances, fibromyalgia remains a challenging condition not only in terms of how it is operationalized and understood by different health professionals but also in terms of its clinical management. We believe this is in part driven by the inherent complexity and multidimensionality that characterizes fibromyalgia and by the lack of a comprehensive framework that integrates current knowledge on the risk and protective factors at play and how they influence the development, expression and course of the disease.

This complexity can only be addressed by adopting a multi-level viewpoint where findings from different disciplines and approaches are brought together and integrated in a coherent way. It is therefore crucial to identify and explore the many interconnections between multiple systems and mechanism known to be altered in FM and how these same dynamic systems come to be modulated by people's genetic makeup, environmental stressors and individual differences.

Only by doing this can we truly gain an in-depth understanding of what fibromyalgia is and how best to treat it. 
Running head: Neurophysiological and psychological dimensions of fibromyalgia

\section{References}

1 Branco, J. C. et al. Prevalence of fibromyalgia: a survey in five European countries. Semin Arthritis Rheum 39, 448-453 (2010).

2 Queiroz, L. P. Worldwide epidemiology of fibromyalgia. Curr Pain Headache Rep 17, 356 (2013).

3 Wolfe, F., Walitt, B., Perrot, S., Rasker, J. J. \& Häuser, W. Fibromyalgia diagnosis and biased assessment: Sex, prevalence and bias. PLoS One 13, e0203755 (2018).

4 Häuser, W. et al. Fibromyalgia. Nat Rev Dis Primers 1, 15022 (2015).

5 Galvez-Sánchez, C. M., Duschek, S. \& Reyes Del Paso, G. A. Psychological impact of fibromyalgia: current perspectives. Psychol Res Behav Manag 12, 117127 (2019).

6 Sicras-Mainar, A. et al. Treating patients with fibromyalgia in primary care settings under routine medical practice: a claim database cost and burden of illness study. Arthritis Res Ther 11, R54 (2009).

7 Schaefer, C. et al. The Comparative Burden of Chronic Widespread Pain and Fibromyalgia in the United States. Pain Pract 16, 565-579 (2016).

8 Wolfe, F. et al. The American College of Rheumatology 1990 Criteria for the Classification of Fibromyalgia. Report of the Multicenter Criteria Committee. Arthritis Rheum 33, 160-172 (1990).

9 Wolfe, F. et al. Fibromyalgia criteria and severity scales for clinical and epidemiological studies: a modification of the ACR Preliminary Diagnostic Criteria for Fibromyalgia. J Rheumatol 38, 1113-1122 (2011).

10 Wolfe, F. et al. 2016 Revisions to the 2010/2011 fibromyalgia diagnostic criteria. Semin Arthritis Rheum 46, 319-329 (2016).

11 Arnold, L. M. et al. AAPT Diagnostic Criteria for Fibromyalgia. J Pain (2018).

12 Williams, D. A. \& Clauw, D. J. Understanding fibromyalgia: lessons from the broader pain research community. J Pain 10, 777-791 (2009).

13 Pinto, A. M. et al. An Integrative Model of Fibromyalgia: Bridging the Gap between Body and Mind (Submitted manuscript).

14 Petersel, D. L., Dror, V. \& Cheung, R. Central amplification and fibromyalgia: disorder of pain processing. J Neurosci Res 89, 29-34 (2011).

15 Lee, Y. C., Nassikas, N. J. \& Clauw, D. J. The role of the central nervous system in the generation and maintenance of chronic pain in rheumatoid arthritis, osteoarthritis and fibromyalgia. Arthritis Res Ther 13, 211 (2011).

16 Sluka, K. A. \& Clauw, D. J. Neurobiology of fibromyalgia and chronic widespread pain. Neuroscience 338, 114-129 (2016).

17 Harte, S. E., Harris, R. E. \& Clauw, D. J. The neurobiology of central sensitization. Journal of Applied Biobehavioral Research 23, e12137 (2018).

18 O'Brien, A. T., Deitos, A., Triñanes Pego, Y., Fregni, F. \& Carrillo-de-la-Peña, M. T. Defective Endogenous Pain Modulation in Fibromyalgia: A Meta-Analysis of Temporal Summation and Conditioned Pain Modulation Paradigms. J Pain 19, 819-836 (2018).

19 Luo, C., Kuner, T. \& Kuner, R. Synaptic plasticity in pathological pain. Trends Neurosci 37, 343-355 (2014).

20 Tan, A. M. et al. Maladaptive dendritic spine remodeling contributes to diabetic neuropathic pain. J Neurosci 32, 6795-6807 (2012).

21 Bliss, T. V., Collingridge, G. L., Kaang, B. K. \& Zhuo, M. Synaptic plasticity in the anterior cingulate cortex in acute and chronic pain. Nat Rev Neurosci 17, 485496 (2016). 
Running head: Neurophysiological and psychological dimensions of fibromyalgia

22 Kim, S. K. \& Nabekura, J. Rapid synaptic remodeling in the adult somatosensory cortex following peripheral nerve injury and its association with neuropathic pain. J Neurosci 31, 5477-5482 (2011).

23 Zhang, K. et al. Remodeling the Dendritic Spines in the Hindlimb Representation of the Sensory Cortex after Spinal Cord Hemisection in Mice. PLoS One 10, e0132077 (2015).

24 Lim, M. et al. Disinhibition of the primary somatosensory cortex in patients with fibromyalgia. Pain 156, 666-674 (2015).

25 Kuchinad, A. et al. Accelerated brain gray matter loss in fibromyalgia patients: premature aging of the brain? J Neurosci 27, 4004-4007 (2007).

26 Gracely, R. H. et al. Pain catastrophizing and neural responses to pain among persons with fibromyalgia. Brain 127, 835-843 (2004).

27 Burgmer, M. et al. Altered brain activity during pain processing in fibromyalgia. Neuroimage 44, 502-508 (2009).

28 Sawaddiruk, P., Paiboonworachat, S., Chattipakorn, N. \& Chattipakorn, S. C. Alterations of brain activity in fibromyalgia patients. J Clin Neurosci 38, 13-22 (2017).

29 Jensen, K. B. et al. Overlapping structural and functional brain changes in patients with long-term exposure to fibromyalgia pain. Arthritis Rheum 65, 3293-3303 (2013).

30 Loggia, M. L. et al. The lateral prefrontal cortex mediates the hyperalgesic effects of negative cognitions in chronic pain patients. J Pain 16, 692-699 (2015).

31 Baliki, M. N., Geha, P. Y., Apkarian, A. V. \& Chialvo, D. R. Beyond feeling: chronic pain hurts the brain, disrupting the default-mode network dynamics. $J$ Neurosci 28, 1398-1403 (2008).

32 Baliki, M. N., Mansour, A. R., Baria, A. T. \& Apkarian, A. V. Functional reorganization of the default mode network across chronic pain conditions. PLoS One 9, e106133 (2014).

33 Woolf, C. J. \& Salter, M. W. Neuronal plasticity: increasing the gain in pain. Science 288, 1765-1769 (2000).

34 Clauw, D. J., Arnold, L. M. \& McCarberg, B. H. The science of fibromyalgia. Mayo Clin Proc 86, 907-911 (2011).

35 Woolf, C. J. Pain amplification-A perspective on the how, why, when, and where of central sensitization. Journal of Applied Biobehavioral Research 23, e12124 (2018).

36 Staud, R. Is it all central sensitization? Role of peripheral tissue nociception in chronic musculoskeletal pain. Curr Rheumatol Rep 12, 448-454 (2010).

37 Sommer, C. \& Üçeyler, N. in Small fiber neuropathy and related syndromes: pain and neurodegeneration (eds. Hsieh, S. T., Anand, P., Gibbons, C.H. \& Sommer, C.) 121-129 (Springer Singapore, Singapore, 2019).

38 Grayston, R. et al. A systematic review and meta-analysis of the prevalence of small fiber pathology in fibromyalgia: Implications for a new paradigm in fibromyalgia etiopathogenesis. Semin Arthritis Rheum (2018).

39 Borchers, A. T. \& Gershwin, M. E. Fibromyalgia: A Critical and Comprehensive Review. Clin Rev Allergy Immunol 49, 100-151 (2015).

40 Staud, R. Peripheral pain mechanisms in chronic widespread pain. Best Pract Res Clin Rheumatol 25, 155-164 (2011).

41 Ruggiero, L., Manganelli, F. \& Santoro, L. Muscle pain syndromes and fibromyalgia: the role of muscle biopsy. Curr Opin Support Palliat Care 12, 382387 (2018). 
Running head: Neurophysiological and psychological dimensions of fibromyalgia

42 Clauw, D. J. What is the meaning of "small fiber neuropathy" in fibromyalgia? Pain 156, 2115-2116 (2015).

43 Oaklander, A. L. What is the meaning of "small-fiber polyneuropathy" in fibromyalgia? An alternate answer. Pain 157, 1366-1367 (2016).

44 Üçeyler, N. Small fiber pathology--a culprit for many painful disorders? Pain 157 Suppl 1, S60-66 (2016).

45 Harte, S. E. et al. Reduced intraepidermal nerve fiber density after a sustained increase in insular glutamate: a proof-of-concept study examining the pathogenesis of small fiber pathology in fibromyalgia. Pain Rep 2, e590 (2017).

46 Adler, G. K. \& Geenen, R. Hypothalamic-pituitary-adrenal and autonomic nervous system functioning in fibromyalgia. Rheum Dis Clin North Am 31, 187202 (2005).

47 Meeus, M. et al. Heart rate variability in patients with fibromyalgia and patients with chronic fatigue syndrome: a systematic review. Semin Arthritis Rheum 43, 279-287 (2013).

48 Staud, R. Heart rate variability as a biomarker of fibromyalgia syndrome. Fut Rheumatol 3, 475-483 (2008).

49 Brosschot, J. F., Verkuil, B. \& Thayer, J. F. Exposed to events that never happen: Generalized unsafety, the default stress response, and prolonged autonomic activity. Neurosci Biobehav Rev 74, 287-296 (2017).

50 Tak, L. M. \& Rosmalen, J. G. Dysfunction of stress responsive systems as a risk factor for functional somatic syndromes. J Psychosom Res 68, 461-468 (2010).

51 McBeth, J. et al. Moderation of psychosocial risk factors through dysfunction of the hypothalamic-pituitary-adrenal stress axis in the onset of chronic widespread musculoskeletal pain: findings of a population-based prospective cohort study. Arthritis Rheum 56, 360-371 (2007).

52 Martinez-Lavin, M. Fibromyalgia: When Distress Becomes (Un)sympathetic Pain. Pain Res Treat 2012, 981565 (2012).

53 Ambrogio, A. G., Pecori Giraldi, F. \& Cavagnini, F. Drugs and HPA axis. Pituitary 11, 219-229 (2008).

54 Baumeister, D., Lightman, S. L. \& Pariante, C. M. The HPA Axis in the Pathogenesis and Treatment of Depressive Disorders: Integrating Clinical and Molecular Findings. Psychopathology Review a3, 64-76 (2016).

55 Koss, K. J. \& Gunnar, M. R. Annual Research Review: Early adversity, the hypothalamic-pituitary-adrenocortical axis, and child psychopathology. Journal of Child Psychology and Psychiatry 59, 327-346 (2018).

56 Generaal, E. et al. Reduced hypothalamic-pituitary-adrenal axis activity in chronic multi-site musculoskeletal pain: partly masked by depressive and anxiety disorders. BMC Musculoskelet Disord 15, 227 (2014).

57 Tak, L. M. et al. Meta-analysis and meta-regression of hypothalamic-pituitaryadrenal axis activity in functional somatic disorders. Biol Psychol 87, 183-194 (2011).

58 van Houdenhove, B. Fibromyalgia and related syndromes characterised by stress intolerance and pain hypersensitivity: Do we need a new nosology? 3, 304-308 (2007).

59 Littlejohn, G. Neurogenic neuroinflammation in fibromyalgia and complex regional pain syndrome. Nat Rev Rheumatol 11, 639-648 (2015).

60 Bäckryd, E., Tanum, L., Lind, A. L., Larsson, A. \& Gordh, T. Evidence of both systemic inflammation and neuroinflammation in fibromyalgia patients, as 
Running head: Neurophysiological and psychological dimensions of fibromyalgia

assessed by a multiplex protein panel applied to the cerebrospinal fluid and to plasma. J Pain Res 10, 515-525 (2017).

61 Littlejohn, G. \& Guymer, E. Neurogenic inflammation in fibromyalgia. Semin Immunopathol 40, 291-300 (2018).

62 Albrecht, D. S. et al. Brain glial activation in fibromyalgia - A multi-site positron emission tomography investigation. Brain Behav Immun (2018).

63 Dell'Osso, L. et al. The inflammatory hypothesis of mood spectrum broadened to fibromyalgia and chronic fatigue syndrome. Clin Exp Rheumatol 33, S109-116 (2015).

64 Young, J. J., Bruno, D. \& Pomara, N. A review of the relationship between proinflammatory cytokines and major depressive disorder. $J$ Affect Disord 169, 15-20 (2014).

65 Pace, T. W. \& Heim, C. M. A short review on the psychoneuroimmunology of posttraumatic stress disorder: from risk factors to medical comorbidities. Brain Behav Immun 25, 6-13 (2011).

66 Michopoulos, V., Powers, A., Gillespie, C. F., Ressler, K. J. \& Jovanovic, T. Inflammation in Fear- and Anxiety-Based Disorders: PTSD, GAD, and Beyond. Neuropsychopharmacology 42, 254-270 (2017).

67 Ignatova, V. in Behavioral neuroscience (eds. Palermo, S. \& Morese, R.) (IntechOpen 2019). https://www.intechopen.com/books/behavioralneuroscience/influence-of-gut-microbiota-on-behavior-and-its-disturbances

68 Kim, Y. K. \& Shin, C. The Microbiota-Gut-Brain Axis in Neuropsychiatric Disorders: Pathophysiological Mechanisms and Novel Treatments. Curr Neuropharmacol 16, 559-573 (2018).

69 Ma, Q. et al. Impact of microbiota on central nervous system and neurological diseases: the gut-brain axis. Journal of Neuroinflammation 16, 53 (2019).

70 Minerbi, A. et al. Altered microbiome composition in individuals with fibromyalgia. Pain (2019).

71 Kato, K., Sullivan, P. F., Evengård, B. \& Pedersen, N. L. Importance of genetic influences on chronic widespread pain. Arthritis Rheum 54, 1682-1686 (2006).

72 Markkula, R. et al. Clustering of symptoms associated with fibromyalgia in a Finnish Twin Cohort. Eur J Pain 13, 744-750 (2009).

73 Buskila, D. \& Neumann, L. Fibromyalgia syndrome (FM) and nonarticular tenderness in relatives of patients with FM. J Rheumatol 24, 941-944 (1997).

74 Arnold, L. M. et al. Family study of fibromyalgia. Arthritis Rheum 50, 944-952 (2004).

75 Buskila, D., Neumann, L., Hazanov, I. \& Carmi, R. Familial aggregation in the fibromyalgia syndrome. Semin Arthritis Rheum 26, 605-611 (1996).

76 Arnold, L. M. et al. The fibromyalgia family study: a genome-wide linkage scan study. Arthritis Rheum 65, 1122-1128 (2013).

77 Glazer, Y., Buskila, D., Cohen, H., Ebstein, R. P. \& Neumann, L. Differences in the personality profile of fibromyalgia patients and their relatives with and without fibromyalgia. Clin Exp Rheumatol 28, S27-32 (2010).

78 Raphael, K. G., Janal, M. N., Nayak, S., Schwartz, J. E. \& Gallagher, R. M. Familial aggregation of depression in fibromyalgia: a community-based test of alternate hypotheses. Pain 110, 449-460 (2004).

79 Park, D. J. \& Lee, S. S. New insights into the genetics of fibromyalgia. Korean J Intern Med 32, 984-995 (2017).

80 Ablin, J. N. \& Buskila, D. Update on the genetics of the fibromyalgia syndrome. Best Pract Res Clin Rheumatol 29, 20-28 (2015). 
Running head: Neurophysiological and psychological dimensions of fibromyalgia

81 Zorina-Lichtenwalter, K., Meloto, C. B., Khoury, S. \& Diatchenko, L. Genetic predictors of human chronic pain conditions. Neuroscience 338, 36-62 (2016).

82 D'Agnelli, S. et al. Fibromyalgia: Genetics and epigenetics insights may provide the basis for the development of diagnostic biomarkers. Mol Pain 15, 1744806918819944 (2019).

83 Lichtenstein, A., Tiosano, S. \& Amital, H. The complexities of fibromyalgia and its comorbidities. Curr Opin Rheumatol 30, 94-100 (2018).

84 Hegazi, M. O. \& Micu, M. C. in Comorbidity in Rheumatic Disea (ed Y. El Miedany) 225-244 (Springer International Publishing, 2017).

85 Kindler, L. L., Bennett, R. M. \& Jones, K. D. Central sensitivity syndromes: mounting pathophysiologic evidence to link fibromyalgia with other common chronic pain disorders. Pain Manag Nurs 12, 15-24 (2011).

86 Phillips, K. \& Clauw, D. J. Central pain mechanisms in chronic pain states--maybe it is all in their head. Best Pract Res Clin Rheumatol 25, 141-154 (2011).

87 Yunus, M. B. Central sensitivity syndromes: a new paradigm and group nosology for fibromyalgia and overlapping conditions, and the related issue of disease versus illness. Semin Arthritis Rheum 37, 339-352 (2008).

88 Yunus, M. B. Editorial review: an update on central sensitivity syndromes and the issues of nosology and psychobiology. Curr Rheumatol Rev 11, 70-85 (2015).

89 Barsky, A. J. \& Borus, J. F. Functional somatic syndromes. Ann Intern Med 130, 910-921 (1999).

90 Maixner, W., Fillingim, R. B., Williams, D. A., Smith, S. B. \& Slade, G. D. Overlapping Chronic Pain Conditions: Implications for Diagnosis and Classification. J Pain 17, T93-T107 (2016).

91 Mease, P. J. Fibromyalgia, a missed comorbidity in spondyloarthritis: prevalence and impact on assessment and treatment. Curr Opin Rheumatol 29, 304-310 (2017).

92 Marrie, R. A. et al. The incidence and prevalence of fibromyalgia are higher in multiple sclerosis than the general population: A population-based study. Mult Scler Relat Disord 1, 162-167 (2012).

93 Di Stefano, G. et al. Central sensitization as the mechanism underlying pain in joint hypermobility syndrome/Ehlers-Danlos syndrome, hypermobility type. Eur J Pain 20, 1319-1325 (2016).

94 Jones, K. D. et al. Genome-wide expression profiling in the peripheral blood of patients with fibromyalgia. Clin Exp Rheumatol 34, S89-98 (2016).

95 Mork, P. J., Vasseljen, O. \& Nilsen, T. I. Association between physical exercise, body mass index, and risk of fibromyalgia: longitudinal data from the Norwegian Nord-Trøndelag Health Study. Arthritis Care Res (Hoboken) 62, 611-617 (2010).

96 Gota, C. E., Kaouk, S. \& Wilke, W. S. Fibromyalgia and Obesity: The Association Between Body Mass Index and Disability, Depression, History of Abuse, Medications, and Comorbidities. J Clin Rheumatol 21, 289-295 (2015).

97 Okifuji, A., Donaldson, G. W., Barck, L. \& Fine, P. G. Relationship between fibromyalgia and obesity in pain, function, mood, and sleep. J Pain 11, 1329-1337 (2010).

98 Kim, C. H., Luedtke, C. A., Vincent, A., Thompson, J. M. \& Oh, T. H. Association of body mass index with symptom severity and quality of life in patients with fibromyalgia. Arthritis Care Res (Hoboken) 64, 222-228 (2012).

99 Ursini, F., Naty, S. \& Grembiale, R. D. Fibromyalgia and obesity: the hidden link. Rheumatology International 31, 1403-1408 (2011). 
Running head: Neurophysiological and psychological dimensions of fibromyalgia

100 Løge-Hagen, J. S. et al. Prevalence of depressive disorder among patients with fibromyalgia: Systematic review and meta-analysis. J Affect Disord 245, 10981105 (2019).

101 Häuser, W., Ablin, J. \& Walitt, B. Comprehensive guide to Post-Traumatic Stress Disorders (eds. Martin, C. R., Preedy, V. R. \& Patel, V. B.) 563-577 (Springer International Publishing, Cham, 2016).

102 Mork, P. J. \& Nilsen, T. I. Sleep problems and risk of fibromyalgia: longitudinal data on an adult female population in Norway. Arthritis Rheum 64, 281-284 (2012).

103 Gupta, A. et al. The role of psychosocial factors in predicting the onset of chronic widespread pain: results from a prospective population-based study. Rheumatology (Oxford) 46, 666-671 (2007).

104 Choy, E. H. The role of sleep in pain and fibromyalgia. Nat Rev Rheumatol 11, 513-520 (2015).

105 Finan, P. H., Goodin, B. R. \& Smith, M. T. The association of sleep and pain: an update and a path forward. J Pain 14, 1539-1552 (2013).

106 Palagini, L. et al. Transdiagnostic factors across fibromyalgia and mental disorders: sleep disturbances may play a key role. A clinical review. Clin Exp Rheumatol 34, S140-144 (2016).

107 Simpson, N. S., Scott-Sutherland, J., Gautam, S., Sethna, N. \& Haack, M. Chronic exposure to insufficient sleep alters processes of pain habituation and sensitization. Pain 159, 33-40 (2018).

108 Viola-Saltzman, M., Watson, N. F., Bogart, A., Goldberg, J. \& Buchwald, D. High prevalence of restless legs syndrome among patients with fibromyalgia: a controlled cross-sectional study. J Clin Sleep Med 6, 423-427 (2010).

109 Attademo, L. \& Bernardini, F. Prevalence of personality disorders in patients with fibromyalgia: a brief review. Prim Health Care Res Dev, 1-6 (2017).

110 Uguz, F. et al. Axis I and Axis II psychiatric disorders in patients with fibromyalgia. Gen Hosp Psychiatry 32, 105-107 (2010).

111 American Psychiatric Association. Diagnostic and Statistical Manual of Mental Disorders, $5^{\text {th }}$ edn. 645-84 (American Psychiatric Association, Arlington, 2013).

112 Bushnell, M. C., Ceko, M. \& Low, L. A. Cognitive and emotional control of pain and its disruption in chronic pain. Nat Rev Neurosci 14, 502-511 (2013).

113 Crofford, L. J. Psychological aspects of chronic musculoskeletal pain. Best Pract Res Clin Rheumatol 29, 147-155 (2015).

114 Peters M.L. E. Pain in psychiatric disorders. Mod Trends Pharmacopsychiatry (eds. Finn, D.P. \& Leonard B.E.) 138-152 (Karger, Basel, 2015).

115 Campbell, C. M. et al. Changes in pain catastrophizing predict later changes in fibromyalgia clinical and experimental pain report: cross-lagged panel analyses of dispositional and situational catastrophizing. Arthritis Res Ther 14, R231 (2012).

116 de Boer, M. J., Struys, M. M. \& Versteegen, G. J. Pain-related catastrophizing in pain patients and people with pain in the general population. Eur J Pain 16, 10441052 (2012).

117 Feliu-Soler, A. et al. Psychometric Properties of the Cognitive Emotion Regulation Questionnaire (CERQ) in Patients with Fibromyalgia Syndrome. Front Psychol 8, 2075 (2017).

118 Ellingson, L. D., Stegner, A. J., Schwabacher, I. J., Lindheimer, J. B. \& Cook, D. B. Catastrophizing Interferes with Cognitive Modulation of Pain in Women with Fibromyalgia. Pain Med 19, 2408-2422 (2018). 
Running head: Neurophysiological and psychological dimensions of fibromyalgia

119 Wiech, K. Deconstructing the sensation of pain: The influence of cognitive processes on pain perception. Science 354, 584-587 (2016).

120 Cedraschi, C. et al. Primary attributions in women suffering fibromyalgia emphasize the perception of a disruptive onset for a long-lasting pain problem. Journal of psychosomatic research 74, 265-269 (2013).

121 Di Tella, M. \& Castelli, L. Alexithymia and fibromyalgia: clinical evidence. Front Psychol 4, 909 (2013).

122 Kool, M. B., van Middendorp, H., Boeije, H. R. \& Geenen, R. Understanding the lack of understanding: invalidation from the perspective of the patient with fibromyalgia. Arthritis Rheum 61, 1650-1656 (2009).

123 Hassett, A. L. et al. The relationship between affect balance style and clinical outcomes in fibromyalgia. Arthritis Rheum 59, 833-840 (2008).

124 Zautra, A. J. et al. Fibromyalgia: evidence for deficits in positive affect regulation. Psychosom Med 67, 147-155 (2005).

125 Cameron, N., Kool, M., Estévez-López, F., López-Chicheri, I. \& Geenen, R. The potential buffering role of self-efficacy and pain acceptance against invalidation in rheumatic diseases. Rheumatol Int 38, 283-291 (2018).

126 van Middendorp, H. et al. Emotions and emotional approach and avoidance strategies in fibromyalgia. J Psychosom Res 64, 159-167 (2008).

127 Sturgeon, J. A. \& Zautra, A. J. Resilience: A New Paradigm for Adaptation to Chronic Pain. Current Pain and Headache Reports 14, 105-112 (2010).

128 Hemington, K. S. et al. Beyond Negative Pain-Related Psychological Factors: Resilience Is Related to Lower Pain Affect in Healthy Adults. J Pain 18, 11171128 (2017).

129 McCracken, L. M. \& Yang, S.-Y. The role of values in a contextual cognitivebehavioral approach to chronic pain. Pain 123, 137-145 (2006).

130 Sturgeon, J. A. \& Zautra, A. J. Psychological Resilience, Pain Catastrophizing, and Positive Emotions: Perspectives on Comprehensive Modeling of Individual Pain Adaptation. Current Pain and Headache Reports 17, 317 (2013).

131 Edwards, R. R., Dworkin, R. H., Sullivan, M. D., Turk, D. C. \& Wasan, A. D. The Role of Psychosocial Processes in the Development and Maintenance of Chronic Pain. J Pain 17, T70-92 (2016).

132 Hassett, A. L. \& Finan, P. H. The Role of Resilience in the Clinical Management of Chronic Pain. Curr Pain Headache Rep 20, 39 (2016).

133 Finan, P. H. \& Garland, E. L. The role of positive affect in pain and its treatment. Clin J Pain 31, 177-187 (2015).

134 Hanssen, M. M., Peters, M. L., Boselie, J. J. \& Meulders, A. Can positive affect attenuate (persistent) pain? State of the art and clinical implications. Curr Rheumatol Rep 19, 80 (2017).

135 Fredrickson, B. L. The role of positive emotions in positive psychology. The broaden-and-build theory of positive emotions. Am Psychol 56, 218-226 (2001).

136 Turk, D. C., Okifuji, A., Sinclair, J. D. \& Starz, T. W. Differential responses by psychosocial subgroups of fibromyalgia syndrome patients to an interdisciplinary treatment. Arthritis Care Res 11, 397-404 (1998).

137 Estévez-López, F. et al. Adaptation profiles comprising objective and subjective measures in fibromyalgia: the al-Ándalus project. Rheumatology (Oxford) 56, 2015-2024 (2017).

138 Zautra, A. J., Johnson, L. M. \& Davis, M. C. Positive affect as a source of resilience for women in chronic pain. J Consult Clin Psychol 73, 212-220 (2005). 
Running head: Neurophysiological and psychological dimensions of fibromyalgia

139 Roy, M. Pain, emotion and cognition: a complex nexus (eds. Pickering, G. \& Gibson, S.) 35-52 (Springer International Publishing, Cham, 2015).

140 Rhudy, J. L. The Neuroscience of pain, stress, and emotion: psychological and clinical implications (eds. Al'Absi, M. \& Flaten, M. A.) 51-75 (Academic Press, 2016).

141 Rhudy, J. L., Williams, A. E., McCabe, K. M., Nguyen, M. A. \& Rambo, P. Affective modulation of nociception at spinal and supraspinal levels. Psychophysiology 42, 579-587 (2005).

142 Rhudy, J. L., McCabe, K. M. \& Williams, A. E. Affective modulation of autonomic reactions to noxious stimulation. Int $J$ Psychophysiol 63, 105-109 (2007).

143 Rhudy, J. L., Williams, A. E., McCabe, K. M., Russell, J. L. \& Maynard, L. J. Emotional control of nociceptive reactions (ECON): do affective valence and arousal play a role? Pain 136, 250-261 (2008).

144 van Middendorp, H. et al. The impact of emotion-related autonomic nervous system responsiveness on pain sensitivity in female patients with fibromyalgia. Psychosom Med 75, 765-773 (2013).

145 Gerdes, A. B., Wieser, M. J. \& Alpers, G. W. Emotional pictures and sounds: a review of multimodal interactions of emotion cues in multiple domains. Front Psychol 5, 1351 (2014).

146 Bartley, E. J., Rhudy, J. L. \& Williams, A. E. Experimental assessment of affective processing in fibromyalgia. J Pain 10, 1151-1160 (2009).

147 Rhudy, J. L. et al. Emotional modulation of pain and spinal nociception in fibromyalgia. Pain 154, 1045-1056 (2013).

148 Kamping, S., Bomba, I. C., Kanske, P., Diesch, E. \& Flor, H. Deficient modulation of pain by a positive emotional context in fibromyalgia patients. Pain 154, 18461855 (2013).

149 Lumley, M. A. et al. Pain and emotion: a biopsychosocial review of recent research. J Clin Psychol 67, 942-968 (2011).

150 deCharms, R. C. et al. Control over brain activation and pain learned by using real-time functional MRI. Proc Natl Acad Sci U S A 102, 18626-18631 (2005).

151 Hassett, A. L. et al. A pilot study of the efficacy of heart rate variability (HRV) biofeedback in patients with fibromyalgia. Appl Psychophysiol Biofeedback 32, 1-10 (2007).

152 Glombiewski, J. A., Bernardy, K. \& Häuser, W. Efficacy of EMG- and EEGBiofeedback in Fibromyalgia Syndrome: A Meta-Analysis and a Systematic Review of Randomized Controlled Trials. Evid Based Complement Alternat Med 2013, 962741 (2013).

153 Dillworth, T., Mendoza, M. E. \& Jensen, M. P. Neurophysiology of pain and hypnosis for chronic pain. Transl Behav Med 2, 65-72 (2012).

154 Jensen, K. B. et al. Cognitive Behavioral Therapy increases pain-evoked activation of the prefrontal cortex in patients with fibromyalgia. Pain 153, 14951503 (2012).

155 Zeidan, F. et al. Brain mechanisms supporting the modulation of pain by mindfulness meditation. J Neurosci 31, 5540-5548 (2011).

156 Y Yoshino, A. et al. Changes in resting-state brain networks after cognitivebehavioral therapy for chronic pain. Psychol Med 48, 1148-1156 (2018).

157 Lazaridou, A. et al. Effects of Cognitive-Behavioral Therapy (CBT) on Brain Connectivity Supporting Catastrophizing in Fibromyalgia. Clin J Pain 33, 215221 (2017). 
Running head: Neurophysiological and psychological dimensions of fibromyalgia

158 Shpaner, M. et al. Unlearning chronic pain: A randomized controlled trial to investigate changes in intrinsic brain connectivity following Cognitive Behavioral Therapy. Neuroimage Clin 5, 365-376 (2014).

159 Feliu-Soler, A. et al. Current status of acceptance and commitment therapy for chronic pain: a narrative review. J Pain Res 11, 2145-2159 (2018).

160 Malin, K. \& Littlejohn, G. O. Personality and fibromyalgia syndrome. Open Rheumatol J 6, 273-285 (2012).

161 Torres, X. et al. Personality does not distinguish people with fibromyalgia but identifies subgroups of patients. Gen Hosp Psychiatry 35, 640-648 (2013).

162 Conversano, C. et al. Personality Traits in Fibromyalgia (FM): Does FM Personality Exists? A Systematic Review. Clin Pract Epidemiol Ment Health 14, 223-232 (2018).

163 Fishbain, D. A. et al. Chronic pain and the measurement of personality: do states influence traits? Pain Med 7, 509-529 (2006).

164 Gustin, S. M. et al. Subtle alterations in brain anatomy may change an individual's personality in chronic pain. PLoS One 9, e109664 (2014).

165 Naylor, B., Boag, S. \& Gustin, S. M. New evidence for a pain personality? A critical review of the last 120 years of pain and personality. Scand J Pain 17, 5867 (2017).

166 Malin, K. \& Littlejohn, G. O. Neuroticism in young women with fibromyalgia links to key clinical features. Pain Res Treat 2012, 730741 (2012).

167 Montoro, C. I. \& Reyes del Paso, G. A. Personality and fibromyalgia: Relationships with clinical, emotional, and functional variables. Personality and Individual Differences 85, 236-244 (2015).

168 Bucourt, E. et al. Comparison of the Big Five personality traits in fibromyalgia and other rheumatic diseases. Joint Bone Spine 84, 203-207 (2017).

169 Nahman-Averbuch, H., Yarnitsky, D., Sprecher, E., Granovsky, Y. \& Granot, M. Relationship between Personality Traits and Endogenous Analgesia: The Role of Harm Avoidance. Pain Pract 16, 38-45 (2016).

170 Garcia-Fontanals, A. et al. Vulnerability to Psychopathology and Dimensions of Personality in Patients With Fibromyalgia. Clin J Pain 33, 991-997 (2017).

171 van Middendorp, H. et al. Prevalence and relevance of Type D personality in fibromyalgia. Gen Hosp Psychiatry 39, 66-72 (2016).

172 Di Tella, M. et al. Pain experience in Fibromyalgia Syndrome: The role of alexithymia and psychological distress. J Affect Disord 208, 87-93 (2017).

173 Martínez, M. P. et al. Relationships between physical symptoms, emotional distress, and pain appraisal in fibromyalgia: the moderator effect of alexithymia. J Psychol 149, 115-140 (2015).

174 Da Silva, J. A. P. et al. Can health care providers recognise a fibromyalgia personality? Clin Exp Rheumatol 35 Suppl 105, 43-49 (2017).

175 Charles, S. T., Gatz, M., Pedersen, N. L. \& Dahlberg, L. Genetic and behavioral risk factors for self-reported joint pain among a population-based sample of Swedish twins. Health Psychol 18, 644-654 (1999).

176 Charles, S. T., Gatz, M., Kato, K. \& Pedersen, N. L. Physical health 25 years later: the predictive ability of neuroticism. Health Psychol 27, 369-378 (2008).

177 Gatchel, R. J., Peng, Y. B., Peters, M. L., Fuchs, P. N. \& Turk, D. C. The biopsychosocial approach to chronic pain: scientific advances and future directions. Psychol Bull 133, 581-624 (2007). 
Running head: Neurophysiological and psychological dimensions of fibromyalgia

178 Häuser, W., Kosseva, M., Uceyler, N., Klose, P. \& Sommer, C. Emotional, physical, and sexual abuse in fibromyalgia syndrome: a systematic review with meta-analysis. Arthritis Care Res (Hoboken) 63, 808-820 (2011).

179 Davis, D. A., Luecken, L. J. \& Zautra, A. J. Are reports of childhood abuse related to the experience of chronic pain in adulthood? A meta-analytic review of the literature. Clin J Pain 21, 398-405 (2005).

180 McBeth, J., Morris, S., Benjamin, S., Silman, A. J. \& Macfarlane, G. J. Associations between adverse events in childhood and chronic widespread pain in adulthood: are they explained by differential recall? J Rheumatol 28, 2305-2309 (2001).

181 Yavne, Y., Amital, D., Watad, A., Tiosano, S. \& Amital, H. A systematic review of precipitating physical and psychological traumatic events in the development of fibromyalgia. Semin Arthritis Rheum 48, 121-133 (2018).

182 Afari, N. et al. Psychological trauma and functional somatic syndromes: a systematic review and meta-analysis. Psychosom Med 76, 2-11 (2014).

183 Burke, N. N., Finn, D. P., McGuire, B. E. \& Roche, M. Psychological stress in early life as a predisposing factor for the development of chronic pain: Clinical and preclinical evidence and neurobiological mechanisms. J Neurosci Res 95, 1257-1270 (2017).

184 Generaal, E. et al. Biological stress systems, adverse life events and the onset of chronic multisite musculoskeletal pain: a 6-year cohort study. Ann Rheum Dis 75, 847-854 (2016).

185 Jay, M., Bendayan, R., Cooper, R. \& Muthuri, S. Lifetime socioeconomic circumstances and chronic pain in later adulthood: findings from a British birth cohort study. BMJ Open (2019).

186 Jones, G. T., Power, C. \& Macfarlane, G. J. Adverse events in childhood and chronic widespread pain in adult life: Results from the 1958 British Birth Cohort Study. Pain 143, 92-96 (2009).

187 You, D. S., Albu, S., Lisenbardt, H. \& Meagher, M. W. Cumulative Childhood Adversity as a Risk Factor for Common Chronic Pain Conditions in Young Adults. Pain Med 20, 486-494 (2019).

188 Nicol, A. L. et al. The Association Between a History of Lifetime Traumatic Events and Pain Severity, Physical Function, and Affective Distress in Patients With Chronic Pain. J Pain 17, 1334-1348 (2016).

189 Wolfe, F. Fibromyalgianess. Arthritis Rheum 61, 715-716 (2009).

190 You, D. S. \& Meagher, M. W. Childhood Adversity and Pain Sensitization. Psychosom Med 78, 1084-1093 (2016).

191 Low, L. A. \& Schweinhardt, P. Early life adversity as a risk factor for fibromyalgia in later life. Pain Res Treat 2012, 140832 (2012).

192 Baumeister, D., Akhtar, R., Ciufolini, S., Pariante, C. M. \& Mondelli, V. Childhood trauma and adulthood inflammation: a meta-analysis of peripheral Creactive protein, interleukin-6 and tumour necrosis factor- $\alpha$. Mol Psychiatry 21, 642-649 (2016).

193 Chen, M. \& Lacey, R. E. Adverse childhood experiences and adult inflammation: Findings from the 1958 British birth cohort. Brain Behav Immun 69, 582-590 (2018).

194 Che, X., Cash, R., Ng, S. K., Fitzgerald, P. \& Fitzgibbon, B. M. A Systematic Review of the Processes Underlying the Main and the Buffering Effect of Social Support on the Experience of Pain. Clin J Pain (2018). 
Running head: Neurophysiological and psychological dimensions of fibromyalgia

195 Baumeister, R. F. \& Leary, M. R. The need to belong: desire for interpersonal attachments as a fundamental human motivation. Psychol Bull 117, 497-529 (1995).

196 Buss, D. M. Evolutionary psychology : the new science of the mind. 6th Edition edn, (Routledge, 2019).

197 Petitte, T. et al. A Systematic Review of Loneliness and Common Chronic Physical Conditions in Adults. Open Psychol J 8, 113-132 (2015).

198 Hawkley, L. C. \& Cacioppo, J. T. Loneliness matters: a theoretical and empirical review of consequences and mechanisms. Ann Behav Med 40, 218-227 (2010).

199 Wolf, L. D. \& Davis, M. C. Loneliness, daily pain, and perceptions of interpersonal events in adults with fibromyalgia. Health Psychol 33, 929-937 (2014).

200 Canaipa, R., Treister, R., Lang, M., Moreira, J. M. \& Castro-Caldas, A. Feeling Hurt: Pain Sensitivity is Correlated With and Modulated by Social Distress. Clin J Pain 32, 14-19 (2016).

201 Jaremka, L. M. et al. Pain, depression, and fatigue: loneliness as a longitudinal risk factor. Health Psychol 33, 948-957 (2014).

202 Karayannis, N. V., Baumann, I., Sturgeon, J. A., Melloh, M. \& Mackey, S. C. The Impact of Social Isolation on Pain Interference: A Longitudinal Study. Ann Behav Med 53, 65-74 (2019).

203 Montoya, P., Larbig, W., Braun, C., Preissl, H. \& Birbaumer, N. Influence of social support and emotional context on pain processing and magnetic brain responses in fibromyalgia. Arthritis Rheum 50, 4035-4044 (2004).

204 Krahé, C., Springer, A., Weinman, J. A. \& Fotopoulou, A. The social modulation of pain: others as predictive signals of salience - a systematic review. Front Hum Neurosci 7, 386 (2013).

205 Franks, H. M., Cronan, T. A. \& Oliver, K. Social support in women with fibromyalgia: Is quality more important than quantity? Journal of Community Psychology 32, 425-438 (2004).

206 Hornstein, E. A. \& Eisenberger, N. I. Unpacking the buffering effect of social support figures: Social support attenuates fear acquisition. PLoS One 12, e0175891 (2017).

207 Kool, M. B. \& Geenen, R. Loneliness in patients with rheumatic diseases: the significance of invalidation and lack of social support. J Psychol 146, 229-241 (2012).

208 Santiago, M. G., Marques, A., Kool, M., Geenen, R. \& da Silva, J. A. P. Invalidation in Patients with Rheumatic Diseases: Clinical and Psychological Framework. J Rheumatol 44, 512-518 (2017).

209 Davis, M. C., Zautra, A. J. \& Reich, J. W. Vulnerability to stress among women in chronic pain from fibromyalgia and osteoarthritis. Ann Behav Med 23, 215-226 (2001).

210 McDermid, A. J., Rollman, G. B. \& McCain, G. A. Generalized hypervigilance in fibromyalgia: evidence of perceptual amplification. Pain 66, 133-144 (1996).

211 Geisser, M. E. et al. A psychophysical study of auditory and pressure sensitivity in patients with fibromyalgia and healthy controls. J Pain 9, 417-422 (2008).

212 Wilbarger, J. L. \& Cook, D. B. Multisensory hypersensitivity in women with fibromyalgia: implications for well being and intervention. Arch Phys Med Rehabil 92, 653-656 (2011). 
Running head: Neurophysiological and psychological dimensions of fibromyalgia

213 Hollins, M. et al. Perceived intensity and unpleasantness of cutaneous and auditory stimuli: an evaluation of the generalized hypervigilance hypothesis. Pain 141, 215-221 (2009).

214 Suhnan, A. P., Finch, P. M. \& Drummond, P. D. Hyperacusis in chronic pain: neural interactions between the auditory and nociceptive systems. Int J Audiol 56, 801-809 (2017).

215 López-Solà, M. et al. Altered functional magnetic resonance imaging responses to nonpainful sensory stimulation in fibromyalgia patients. Arthritis Rheumatol 66, 3200-3209 (2014).

216 López-Solà, M. et al. Towards a neurophysiological signature for fibromyalgia. Pain 158, 34-47 (2017).

217 Borg, C., Emond, F. C., Colson, D., Laurent, B. \& Michael, G. A. Attentional focus on subjective interoceptive experience in patients with fibromyalgia. Brain Cogn 101, 35-43 (2015).

218 Rost, S., Van Ryckeghem, D. M., Schulz, A., Crombez, G. \& Vögele, C. Generalized hypervigilance in fibromyalgia: Normal interoceptive accuracy, but reduced self-regulatory capacity. J Psychosom Res 93, 48-54 (2017).

219 Carrillo-de-la-Peña, M. T., Vallet, M., Pérez, M. I. \& Gómez-Perretta, C. Intensity dependence of auditory-evoked cortical potentials in fibromyalgia patients: a test of the generalized hypervigilance hypothesis. J Pain 7, 480-487 (2006).

220 Peters, M. L., Vlaeyen, J. W. \& van Drunen, C. Do fibromyalgia patients display hypervigilance for innocuous somatosensory stimuli? Application of a body scanning reaction time paradigm. Pain 86, 283-292 (2000).

221 Tiemann, L. et al. Behavioral and neuronal investigations of hypervigilance in patients with fibromyalgia syndrome. PLoS One 7, e35068 (2012).

222 Carrillo-de-la-Peña, M. T., Triñanes, Y., González-Villar, A., Gómez-Perretta, C. \& García-Larrea, L. Filtering out repetitive auditory stimuli in fibromyalgia: a study of P50 sensory gating. Eur J Pain 19, 576-584 (2015).

223 Mehling, W. E. et al. Body awareness: construct and self-report measures. PLoS One 4, e5614 (2009).

224 Valenzuela-Moguillansky, C., Reyes-Reyes, A. \& Gaete, M. I. Exteroceptive and Interoceptive Body-Self Awareness in Fibromyalgia Patients. Front Hum Neurosci 11, 117 (2017).

225 Yunus, M. B. Gender differences in fibromyalgia and other related syndromes. $J$ Gend Specif Med 5, 42-47 (2002).

226 Popescu, A., LeResche, L., Truelove, E. L. \& Drangsholt, M. T. Gender differences in pain modulation by diffuse noxious inhibitory controls: a systematic review. Pain 150, 309-318 (2010).

227 Racine, M. et al. A systematic literature review of 10 years of research on sex/gender and experimental pain perception - part 1: are there really differences between women and men? Pain 153, 602-618 (2012).

228 Bartley, E. J. \& Fillingim, R. B. Sex differences in pain: a brief review of clinical and experimental findings. Br J Anaesth 111, 52-58 (2013).

229 Mogil, J. S. Sex differences in pain and pain inhibition: multiple explanations of a controversial phenomenon. Nat Rev Neurosci 13, 859-866 (2012).

230 Racine, M. et al. A systematic literature review of 10 years of research on sex/gender and pain perception - part 2: do biopsychosocial factors alter pain sensitivity differently in women and men? Pain 153, 619-635 (2012).

231 Rhudy, J. L. et al. Do sex hormones influence emotional modulation of pain and nociception in healthy women? Biol Psychol 94, 534-544 (2013). 
Running head: Neurophysiological and psychological dimensions of fibromyalgia

232 Bernardes, S. F., Keogh, E. \& Lima, M. L. Bridging the gap between pain and gender research: a selective literature review. Eur J Pain 12, 427-440 (2008).

233 Fillingim, R. B., Edwards, R. R. \& Powell, T. Sex-dependent effects of reported familial pain history on recent pain complaints and experimental pain responses. Pain 86, 87-94 (2000).

234 Fillingim, R. B. \& Edwards, R. R. Is self-reported childhood abuse history associated with pain perception among healthy young women and men? Clin J Pain 21, 387-397 (2005). 